\title{
Dorsal striatal dopamine induces fronto-cortical hypoactivity and attenuates anxiety and compulsive behaviors in rats
}

\author{
Agata Casado-Sainz ${ }^{1,10}$, Frederik Gudmundsen ${ }^{1,10}$, Simone L. Baerentzen ${ }^{1}$, Denise Lange ${ }^{2}$, Annemette Ringsted ${ }^{1}$, \\ Isabel Martinez-Tejada ${ }^{1}$, Siria Medina ${ }^{1}$, Hedok Lee ${ }^{3}$, Claus Svarer (D) $^{1}$, Sune H. Keller ${ }^{4}$, Martin Schain ${ }^{1}$, Celia Kjaerby ${ }^{5}$, Patrick M. Fisher ${ }^{1}$, \\ Paul Cumming ${ }^{6,7}$ and Mikael Palner ${ }^{1,8,9}$
}

(c) The Author(s), under exclusive licence to American College of Neuropsychopharmacology 2021

Dorsal striatal dopamine transmission engages the cortico-striato-thalamo-cortical (CSTC) circuit, which is implicated in many neuropsychiatric diseases, including obsessive-compulsive disorder (OCD). Yet it is unknown if dorsal striatal dopamine hyperactivity is the cause or consequence of changes elsewhere in the CSTC circuit. Classical pharmacological and neurotoxic manipulations of the CSTC and other brain circuits suffer from various drawbacks related to off-target effects and adaptive changes. Chemogenetics, on the other hand, enables a highly selective targeting of specific neuronal populations within a given circuit. In this study, we developed a chemogenetic method for selective activation of dopamine neurons in the substantia nigra, which innervates the dorsal striatum in the rat. We used this model to investigate effects of targeted dopamine activation on CSTC circuit function, especially in fronto-cortical regions. We found that chemogenetic activation of these neurons increased movement (as expected with increased dopamine release), rearings and time spent in center, while also lower self-grooming. Furthermore, this activation increased prepulse inhibition of the startle response in females. Remarkably, we observed reduced $\left[{ }^{18} \mathrm{~F}\right] \mathrm{FDG}$ metabolism in the frontal cortex, following dopamine activation in the dorsal striatum, while total glutamate levels- in this region were increased. This result is in accord with clinical studies of increased $\left[{ }^{18} \mathrm{~F}\right] \mathrm{FDG}$ metabolism and lower glutamate levels in similar regions of the brain of people with OCD. Taken together, the present chemogenetic model adds a mechanistic basis with behavioral and translational relevance to prior clinical neuroimaging studies showing deficits in fronto-cortical glucose metabolism across a variety of clinical populations (e.g. addiction, risky decision-making, compulsivity or obesity).

Neuropsychopharmacology (2022) 47:454-464; https://doi.org/10.1038/s41386-021-01207-y

\section{INTRODUCTION}

The cortico-striato-thalamo-cortical CSTC circuit relays and shapes neocortical activity through the striatum, midbrain, and thalamus back to the cortex. In this circuit, cortical pyramidal neurons project to the dorsal striatum, where spiny projection neurons (SPN) then subserve an integration of direct (go) or indirect (no-go) output pathways that relay signals to the thalamus via the substantia nigra pars reticulata $(\mathrm{SNr})$. The thalamus then communicates the processed signal back to the frontal cortex to complete the circuit $[1,2]$. The activity of the CSTC circuit is modulated by nigro-striatal dopamine projections to the dorsal striatum. Changes in striatal dopaminergic activity have been linked to perturbations of cognitive functions in multiple neuropsychiatric or neurodegenerative diseases [3] such as obsessive-compulsive disorder (OCD) [2] and schizophrenia [4]. While showing distinct phenomenologies, these conditions have overlapping behavioral phenotypes, including obsessions, compulsions, and sensory gating deficits, which are linked to altered dopaminergic transmission within the striatum $[5,6]$.

Molecular imaging studies by positron emission tomography (PET) in people with OCD have shown changes in striatal dopamine receptor availability [6], as well as metabolic hyperactivity especially in the orbitofrontal cortex (OFC) and increased metabolic connectivity from frontal cortex to the caudate nucleus [7-10], which is the equivalent of the medial dorsal striatum (mDS) in rodents [11]. MR spectroscopy studies of such individuals have shown relatively reduced total glutamate + glutamine (GIx) and $\mathrm{N}$-acetylaspartate (NAA) levels in fronto-cortical regions [12-14]. These clinical imaging studies suggest the presence of a phenotype of abnormal CSTC circuit activity in OCD, although it is difficult to establish causal relationships based on clinical imaging without direct targeting of specific neuronal pathways. As such, it is unclear if altered striatal dopamine function is a driver for or rather a consequence of fronto-cortical dysfunction in

\footnotetext{
${ }^{1}$ Neurobiology Research Unit, Copenhagen University Hospital, Copenhagen, Denmark. ${ }^{2}$ Department of Sleep and Human Factors Research, Institute of Aerospace Medicine,

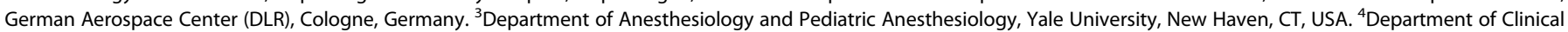

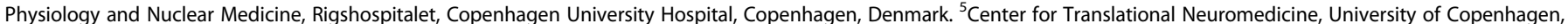

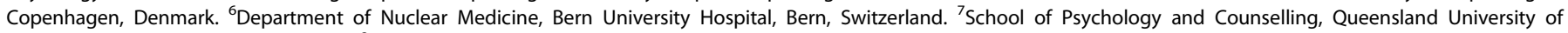

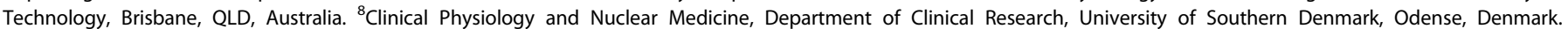

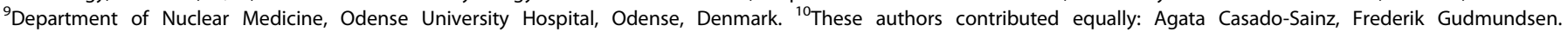
email: mikael.palner@nru.dk
} 
neuropsychiatric disease. Furthermore, it is unclear how dorsal striatal dopamine dysfunction might contribute to the behavioral changes reported in a variety of clinical conditions marked by behavioral disinhibition (e.g., substance addiction, risky decisionmaking or gambling, compulsivity or obesity).

Classical neurochemical approaches to modulate activity within the rodent CSTC circuit include neurochemical lesions [15, 16], and focal stereotaxic drug injections [17]. These chronic methods bring, in varying degrees, unintended perturbations or adaptive changes of the nervous system. Chemogenetics, on the other hand, enables a highly selective targeting of specific neuronal populations within a given circuit. In this study, we applied a selective retrograde chemogenetic transduction of the mDS dopamine projections arising from the medial substantia nigra pars compacta (mSNpc). Using this model, we studied the effects of selective nigro-striatal dopamine activation on behavioral and whole-brain cerebral metabolic activity in the rodent brain. The combination of $\left[{ }^{18} \mathrm{~F}\right]$ FDG PET and MR spectroscopy gives valuable knowledge highly needed in order to interpret clinical neuroimaging findings in psychiatric disorders, such that their combined use through hybrid PET/MR technology in patients may increase our understanding of such disorders. We obtained [ $\left.{ }^{18} \mathrm{~F}\right] \mathrm{FDG}$ PET and MR spectroscopy data in the chemogenetically activated rats, and tested for changes in behaviors related to CTSC function. As such, we tested the novel hypothesis that potentiating dopaminergic activity specifically in mDS will perturb metabolism in the CTSC circuit, while reducing anxiety and compulsion-like behavioral symptoms resembling those present in disorders such as OCD.

\section{MATERIALS AND METHODS}

\section{Animals}

Long Evans TH:Cre rats (LE Tg(TH:Cre 3.1)Deis) were purchased from the Rat Resource and Research Center (RRRC, University of Missouri). This strain carries a transgene containing a Cre recombinase inserted immediately before the start codon of the tyrosine hydroxylase gene [18]. Both male $(\boldsymbol{\sigma}=\mathbf{\Delta})$ and female $(\boldsymbol{Q}=\boldsymbol{\nabla})$ animals were used. Additional information on breeding and ethics is presented in the Supplementary Materials. We conducted all procedures in accordance with the FELASA guidelines and with approval from The Danish Animal Experiments Inspectorate (license number: 2016-15-0201-01031). GMO procedures were approved by the Danish Working Environment Authority (Lab ID 229 806).

\section{Statistics}

Results were analyzed in GraphPad using a two-way ANOVA (behavioral experiments) or mixed effects model (PET and MRS) analysis with repeated measures-where appropriate-with adjustment for multiple comparisons. When relevant, we report general effects of sex, treatment or vector injection with significance $(P)$ and degrees of freedom $(F)$, while mixed effects models are noted with $t$-value and degrees of freedom (DF). Individual group differences are noted with respect to significance $(P)$. Standard deviations (SD) are reported throughout the results and figures. Significance is reported as ${ }^{* * *} P<0.0001,{ }^{* * *} P<0.001,{ }^{* *} P<0.01,{ }^{*} P<0.05$. Graphpad Prism files containing all tests, data, and figures are available upon reasonable request.

\section{Retrograde chemogenetic transduction of dopaminergic projections in rats and mice}

Adult TH:Cre rats $(250 \mathrm{~g})$ were anesthetized with $3 \%$ isoflurane $(\mathrm{vol} / \mathrm{vol})$ in oxygen and placed into a stereotactic frame (Kopf Instruments, Tujunga, CA, USA). Anesthesia was maintained with $1.5-2 \%$ isoflurane; breathing, pain reflex, and body temperature were monitored throughout surgery. The scalp was shaved and disinfected with successive swabs soaked in $70 \%$ iodine, ethanol, and $0.1 \%$ lidocaine. An incision was then made down the midline of the scalp, the skull was exposed, and burr holes were drilled above the target regions. The DREADD (mDS-DREADD: AAV6-hSyn-DIOmCherry-hM3D(Gq)-WPRE) (hM3Dq) and mCherry (mDS-mCherry: AAV6hSyn-DIO-mCherry-WPRE) carrying viral vectors (described in detail in the
Supplementary Materials) were injected bilaterally in the $\mathrm{mDS}$ at two locations in each hemisphere $(2 \mu \mathrm{L}$ per location) (AP $+1.1 \mathrm{~mm}, \mathrm{ML} \pm 2.5$ $\mathrm{mm}, \mathrm{DV}-5 \mathrm{~mm}$ and $-6 \mathrm{~mm}$, from bregma), via a $10 \mu \mathrm{l}$ Nanofil syringe and 33GA beveled needle (World Precision Instruments, Sarasota, FL, USA) at an infusion rate of $150 \mathrm{~nL} / \mathrm{min}$. After infusion, the needle was left in place for $10 \mathrm{~min}$ to allow for diffusion of the virus away from the needle tip before its slow withdrawal. Following injections, the scalp was sutured, and the rats were allowed to regain consciousness. Carprofen $(5 \mathrm{mg} / \mathrm{kg})$ was administered subcutaneously as an analgesic before surgery and at 24 and $48 \mathrm{~h}$ after surgery. Following surgery, rats were single-housed for 1 week, and their weight, fur, eyes and overall movement were checked daily for signs of distress following the scheme of Roughan and Flecknell [19]. Animals were then returned to group housing for 2 weeks prior to further experiments.

\section{Immunohistochemistry}

At the end of the experiments, rats were euthanized with an overdose of pentobarbital and immediately perfused transcardially with $150-200 \mathrm{ml}$ of ice-cold phosphate-buffered saline (PBS, pH 7.4) followed by $100-150 \mathrm{ml}$ of ice-cold $4 \%$ paraformaldehyde in PBS. Brains were removed and stored in $4 \%$ paraformaldehyde for $24 \mathrm{~h}$ at $4{ }^{\circ} \mathrm{C}$, rinsed twice with PBS, and then cryoprotected in $30 \%$ sucrose/PBS. Brain sections $40-\mu \mathrm{m}$ thick obtained on a microtome were stored in cryoprotectant solution at $-20^{\circ} \mathrm{C}$. Freefloating sections were immunostained for mCherry (Cat. \#632543, TaKaRa Bio Europe) using the Avidin-Biotin Complex Peroxidase method and for TH (Cat. \#P21962, Invitrogen) using fluorescent antibodies as described in detail in the Supplementary Material.

\section{Behavioral assesment}

First, we assessed the individual acoustic startle responses of the rats as described in detail in the Supplementary Material. On the experimental day, locomotor activity and prepulse inhibition (PPI) of the acoustic startle response were recorded from 43 animals in cohort 1 at baseline and again after clozapine $\mathrm{N}$-oxide (CNO) treatment (14 WT (7M/7F), 15 mDS-DREADD $(8 \mathrm{M} / 7 \mathrm{~F})$ and $14 \mathrm{mDS}-\mathrm{mCherry}$ rats $(7 \mathrm{M} / 7 \mathrm{~F}))$, see Supplementary Material for a description of the experimental setup (Fig. S1). Locomotor activity was assessed in a custom-made open field maze consisting of an $80 \times 80$ $\mathrm{cm}$ arena enclosed by $65 \mathrm{~cm}$ opaque walls, with indirect, dim illumination ( 10 Lux). On the test day, rats received an i.p. injection of CNO $(0.5 \mathrm{mg} / \mathrm{kg}$ in $5 \% \mathrm{DMSO} /$ Saline), and $20 \mathrm{~min}$ later were placed at the center of the open field and allowed to explore for $40 \mathrm{~min}$. Behavior was recorded with a Basler ace2 Pro video camera with a $4.5-12.5 \mathrm{~mm}$ F1.2 lens positioned directly above the arena and analyzed using Ethovision software, with scoring of distance, velocity, center of field entries, rearing and grooming. The arena was cleaned with soap and water and then dried between each session. Immediately after the locomotion recordings, the rats were transferred to the startle chamber for sensorimotor gating assessment, details of which are described in the Supplementary Material.

\section{$\left[{ }^{18}\right.$ F]FDG PET scanning}

The rats $(n=14,(7 \mathrm{mDS}$-DREADD, 4F/3M), (7 mDS-mCherry, 4F/3M)) were fasted overnight before the PET scan. On the day of the experiment, they received an s.c. injection of $0.5 \mathrm{mg} / \mathrm{kg}$ CNO $(0.5 \mathrm{mg} /$ $\mathrm{kg}$ in $5 \% \mathrm{DSMO} /$ Saline) or saline followed 20 min later by an i.p. injection of $14.1 \pm 1.6 \mathrm{MBq}$ FDG (from the clinical in-house production). The rats remained in their home cage for $45 \mathrm{~min}$ following the $\left[{ }^{18} \mathrm{~F}\right] \mathrm{FDG}$ injection. Following this uptake period, the rats were sedated with isoflurane (2-2.5\% in oxygen) and placed in a homemade four-rat insert in a Siemens HRRT (High Resolution Research Tomograph) scanner [20] for a 45-min list-mode emission scan. The rats were kept warm using an infrared lamp and monitored for respiration throughout the scan. PET images were cropped to brain-only images for each rat and manually coregistration to an FDG-specific rat brain template. Individual scans were converted to SUV units and normalized to whole-brain uptake as described in detail in the Supplementary Material. The images were averaged per group/condition and maps of the voxel-wise difference were calculated between conditions. We undertook a regional analysis for each animal in nucleus accumbens (NAc), $\mathrm{mDS}$, lateral dorsal striatum (IDS), anterior cingulate cortex (ACC), mPFC, OFC, thalamus (Thal), the midbrain including ventral tegmental area and substantia nigra (MB), hypothalamus (Hyp) and cerebellum (Cer), as described in detail in the Supplementary Material. 
456

\section{Magnetic resonance spectroscopy}

All MR scans were performed on a Bruker BioSpec 94/30 USR MRI system $(9.4 \mathrm{~T}, 30 \mathrm{~cm}$ bore, Bruker, Germany) as previously described [21]. In short, rats were anaesthetized with $2 \%(\mathrm{vol} / \mathrm{vol})$ isoflurane in oxygen, MRS was done sequentially in a $3 \times 3 \times 3 \mathrm{~mm}$ region in the right hemispheric $\mathrm{mDS}$ and then in a $3 \times 2 \times 3 \mathrm{~mm}$ region in $\mathrm{mPFC}$. The spectra were acquired using a STEAM sequence with $\mathrm{TE}=4 \mathrm{~ms}, \mathrm{TR}=4000 \mathrm{~ms}$, 400 averages, eight dummy scans and 4096 points. VAPOR was used for water suppression. Metabolite concentrations were calculated with LCModel using water unsuppressed signal as an internal reference.

\section{RESULTS \\ Selective chemogenetic targeting of nigro-striatal dopaminergic projections}

We first confirmed the retrograde transduction of nigro-striatal dopamine neurons. Injection of Cre-dependent serotype 6 adeno associated viruses in the $\mathrm{mDS}$ of $\mathrm{TH}: \mathrm{Cre}$ rats led to selective retrograde expression of the mCherry reporter gene in dopamine projection neurons arising from the mSNpc (Fig. 1A, B). Immunohistochemical identification of the mCherry reporter gene showed excellent selectivity towards the target neurons (Fig. 1C). Two different viral vectors were injected into the $\mathrm{mDS}$, one carrying a Gq-coupled DREADD together with mCherry and the other only mCherry (Fig. 1D). Overall, this produced a highly reproducible target transduction in the mDS (Fig. S2A) with similar distance from the ventricles (Fig. S2B), with a lower staining intensity (Fig. S2C) $(P<0.0001, n=86)$ and spread from the injection site (Fig. S2D) $(P<0.0001, n=86)$ noted for the hM3Dq-carrying vector. There was no evident transduction of cell bodies resident in the $\mathrm{mDS}$, nor of non-TH:Cre-positive cells in the mSNpc (Fig. 1E-J). Notably, the ventral tegmental area was devoid of mCherry-expressing somata (Fig. 1E, I).

\section{Nigro-striatal dopaminergic stimulation increases exploratory behaviors and lowers self-grooming}

We then tested the efficacy of our transduction by locomotor activity. There were no effects of sex on either behavior, and as such the results from each sex are pooled in the graphs displayed in Fig. 2, where sex is denoted as male $(\hat{o}=\mathbf{\Delta})$ and female $(q=\boldsymbol{\nabla})$. Graphs displaying the time spent in behaviors are also shown for each sex in the Supplementary Material (Fig. S4) for ease of viewing changes in individual sexes. CNO significantly increased velocity in mDS-DREADD animals $(P<0.0001, F(1,14)=46.8)$, with a maximal $90 \%$ increase occurring after $20 \mathrm{~min}$ of exploration, as compared to $\mathrm{mDS}$-mCherry animals, while a small decrease was noted in wildtype (WT) rats $(P=0.006, F(1,11)=11.8)$ (Fig. 2A, B). The mDS-DREADD rats showed an increase in total distance traveled (Fig. 2C, D) $(P<0.0001, n=12)$ and total time spent $(P<$ $0.0001, n=12$ ) in locomotion (Fig. 2E). Wildtype (WT) rats had a $14 \%$ decrease in locomotion time $(P=0.0008, n=13)$ following CNO treatment, which we attribute to a general habituation to the open field during the second exposure (Fig. 2E). Yet, the number of movement initiations (frequency) was similar in all groups (Fig. 2I). There was an increased number of entries (Fig. 2F) $(+125 \%, P<0.0001, n=12)$ and time spent (Fig. $2 \mathrm{~J})(+119 \%, P<$ $0.0001, n=12$ ) in the center of the open field for mDS-DREADD rats following CNO treatment. Time spent rearing (Fig. 2G) and number of rearing events (Fig. 2K) were similarly increased by $66 \%$ $(P<0.001, n=12)$ and $99 \%(P<0.001, n=12)$, respectively following $\mathrm{CNO}$ treatment in mDS-DREADD rats. Self-grooming time (Fig. $2 \mathrm{H}$ ) and bouts (Fig. 2L) were likewise affected, but in the opposite direction, with significant reductions of $-59 \%(P<0.001$, $n=12)$ and $-38 \%(P<0.001, n=12)$ respectively, after CNO treatment. Similarly, for the second batch of animals used for the imaging experiments, there was a similar increase in total movement (Fig. S3A) $(P=0.003, n=9)$, center entries (Fig. S3B) $(P=0.005, n=9)$ and rearing (Fig. S3C) $(P=0.002, n=9)$ in mDSDREADD animals following CNO treatment. There were no main effects of transduction on either behavior. Taken together, mDSDREADD rats moved and explored more following CNO treatment compared to WT and mDS-mCherry rats, while spending less time self-grooming.

\section{Nigro-striatal dopaminergic stimulation affects prepulse inhibition of the acoustic startle response differently in males and females}

PPI of the acoustic startle response is modulated by CSTC circuit function and impaired in OCD and other neuropsychiatric disorders [22-24]. To assess PPI, we first tested basal acoustic startle response (SR) to different intensity sound pulses. The SR was clearly measurable after exceeding $100 \mathrm{~dB}$ amplitude and plateaued at $110 \mathrm{~dB}$ both in males and females (Fig. 3A), with a maximal SR (as measured at $120 \mathrm{~dB}$ ) of $59.1 \pm 8.1 \%$ in males $(n=$ 21 ) and $49.6 \pm 9.1 \%$ in females $(n=27)$. We thus chose $110 \mathrm{~dB}$ as the pulse intensity for subsequent testing of PPI. There was a sex difference in the SR to various volumes of sound pulses $(P<0.001$, $F(1,46)=25.2$ ), but no effect of transductions (Fig. 3B, C).

We then tested SR to a $110 \mathrm{~dB}$ sound pulse with or without different intensity prepulses (all pulses are shown in Fig. S5A, D) and short-term habituation (STH) (Fig. S5B, E). There was no effect of transductions or treatment with CNO on the SR (Fig. 3D, E), but there was an overall effect of sex. SR was greater in males $(58.1 \pm$ $3.8 \%, n=21)$ than in females $(48.6 \pm 4.3 \%, n=27)(P<0.001, F$ $(1,84)=30.64)$, as expected from the initial SR test (Fig. 3A). There were no differences in mean STH between WT and transduction groups or between baseline and CNO treatment (Fig. S5B, E). However, the mean STH was significant in all female groups combined (19.7 $\pm 6.2 \% ; n=27)$ (Fig. S5E) $(P=0.008, F(1,86)=7.3)$. In general, SRs decreased in proportion to the amplitude of the prepulse, as expected (Fig. S5A, D). There were no general effects of transduction or CNO treatment on SR in either sex. Yet, a reduced SR following CNO treatment in $\mathrm{mDS}$-DREADD females was just shy of statistical significance (Ave. Diff. $=3.3 \pm 1.5 \%, P=$ $0.0501(F(1,9)=5.11))$ and mDS-DREADD male rats showed a higher SR following CNO treatment to the $81 \mathrm{~dB}$ prepulse alone, which probably reflects increased movement rather than actual SR (Fig. $\mathrm{S} 5 \mathrm{H})$. We next assessed the latency from startle pulse to startle onset and maximum peak of startle from the SR data above (Fig. S5C, F). There were no differences in latency in any condition.

The resulting PPI showed a general $24 \%$ increase in $\mathrm{mDS}$ DREADD female rats for all pre-pulses amplitudes $(P=0.022, F$ $(1,9)=7.6)$ (Fig. 3G), and a $58 \%$ increase in female mDS-DREADD rats at the $69 \mathrm{~dB}$ prepulse condition upon CNO treatment (Fig. 3) $(P=0.018, n=10)$. There were no changes in male rats (Fig. $3 \mathrm{~F}, \mathrm{H})$. Baseline PPI following the $69 \mathrm{~dB}$ prepulse was higher in female than male rats (Fig. S5G) $(P=0.006, F(1,84)=7.86)$. Transduction did not affect baseline PPI

\section{Nigro-striatal dopaminergic stimulation affects metabolic activity in the medial prefrontal cortex and orbitofrontal cortex}

Next, we wanted to know how dorsal striatal dopamine affected clinical neuroimaging measurements often used to study neuropsychiatric disorders. We used a whole-brain $\left[{ }^{18} \mathrm{~F}\right]$ FDG PET approach to assess the glucose metabolism in the whole CSTC circuit at once. An image analysis of voxel intensity showed a relative lower uptake of $\left[{ }^{18} \mathrm{~F}\right] \mathrm{FDG}$ in cortical regions and higher uptake in cerebellar regions in mDS-DREADD rats after CNO treatment (Fig. 4A). On a CSTC regional level, there were significant reductions in $\left[{ }^{18} \mathrm{~F}\right] \mathrm{FDG}$ uptake in the $\mathrm{mPFC}(-9 \%$, $P=0.002, t=4.06, \mathrm{DF}=60, N=7)$ and OFC $(-8 \%, P=0.004, t=$ 3.73, $\mathrm{DF}=49, N=8$ ) following CNO treatment in mDS-DREADD rats (Fig. 4B, C). There were no effects on $\left[{ }^{18} \mathrm{~F}\right] \mathrm{FDG}$ uptake in other CSTC regions of $m D S-D R E A D D$, nor in $\mathrm{mDS}$-mCherry rats (Fig. $4 \mathrm{~B}$ ), and no effects of sex or transduction. A post hoc correlation 


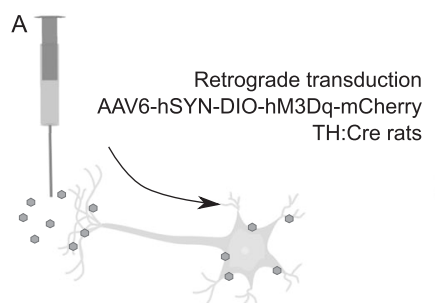

D

mCherry viral vector
B
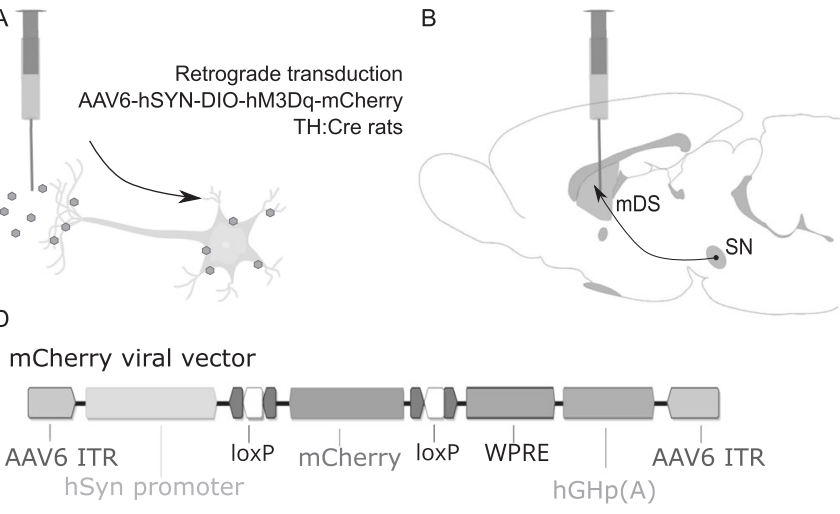

DREADD viral vector
C

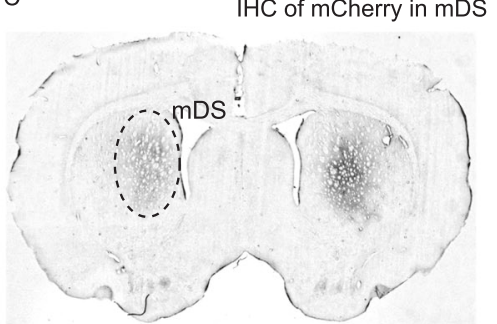

IHC of mCherry in SN
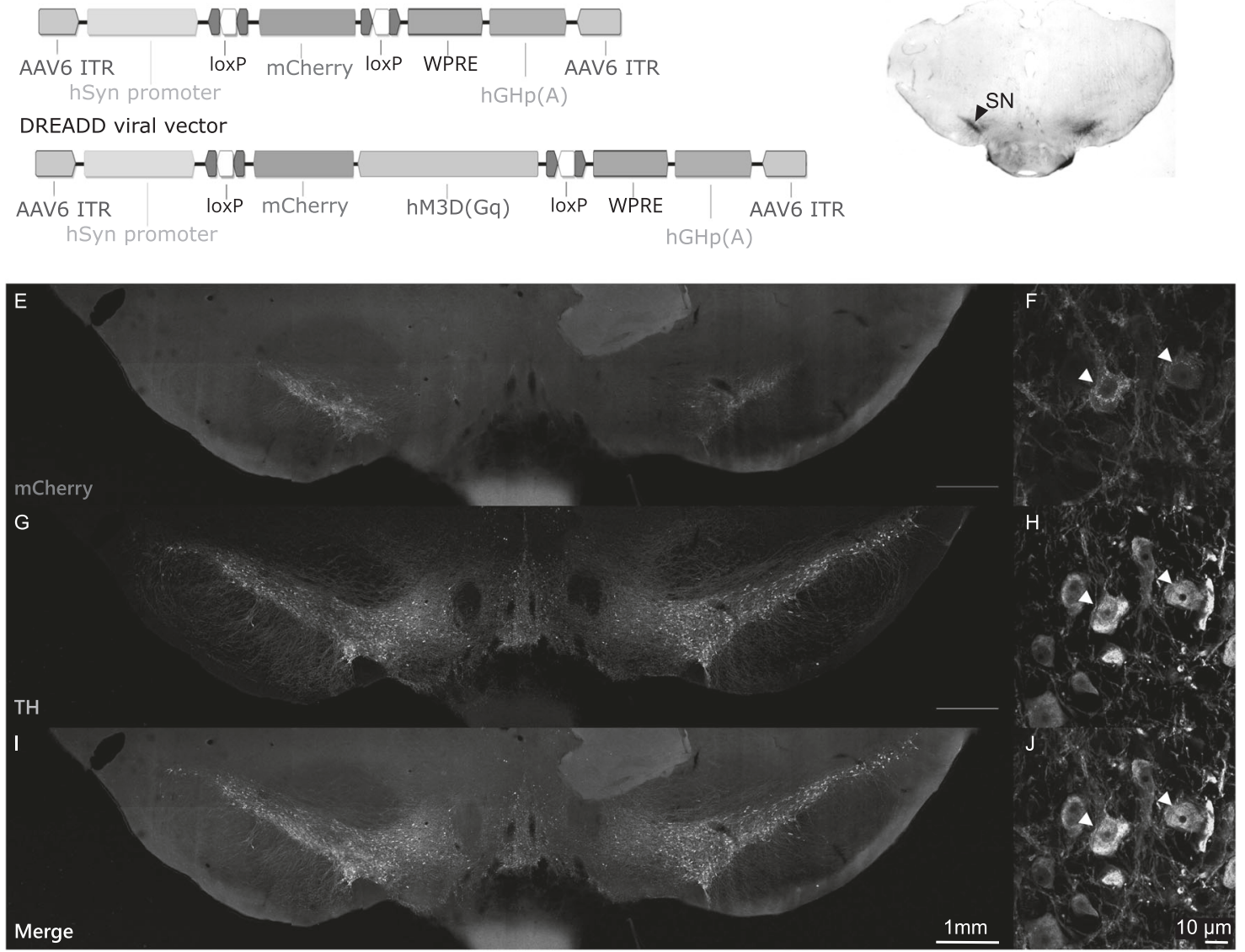

Fig. 1 Validation of transductions. A, B Retrograde transduction of Cre-positive tyrosine hydroxylase (TH) expressing neurons in the dorsomedial striatum. C Immunohistochemical staining of mCherry in dorsomedial striatum and in substantia nigra. D Viral vectors used in the vehicle (mDS-mCherry) and chemogenetic (mDS-DREADD) transduction groups. E, G, I Fluorescent microscopy of mCherry (viral transducted) and TH-positive (dopamine) cells in the mesencephalon. F, H, J Magnifications of individual transducted cells (two examples labeled with white arrows) in the SN.

analysis between regions in the CSTC circuit did not yield significant differences in the correlations between mDS-DREADD baseline or CNO treated animals (Fig. 4D, E). However, it is notable that the largest changes in correlations we found between the cortical regions (OFC, ACC, and $\mathrm{mPCF}$ ) and dorsal striatal regions ( $\mathrm{mDS}$ and IDS), as well as intracortical (ACC-OFC) and subcortical correlations NAc-Thal (Fig. 4F).

\section{Nigro-striatal dopaminergic stimulation increase glutamate and $\mathrm{N}$-acetylaspartylglutamic acid in medial prefrontal cortex and glutamate levels in dorsal striatum}

Based on the $\left[{ }^{18} \mathrm{~F}\right]$ FDG PET findingsabove, we chose two regions (mPFC and DS) for MR spectroscopy (MRS) measurements of glutamate (Glu) plus glutamine (Gln), N-aspartate (NAA), and $\mathrm{N}$-acetylaspartylglutamic acid (NAAG) in vivo. There were significant increases in glutamate $(P<0.0001, t=5.73, \mathrm{DF}=70)$, total $\mathrm{NAA}+\mathrm{NAAG}(P=0.006, t=3.43, \mathrm{DF}=70)$ and total glutamate + glutamine $(P=0.001, t=3.95, \mathrm{DF}=70)$ levels in the $\mathrm{mPFC}$ following CNO treatment in mDS-DREADD rats (Fig. 5D, E). Furthermore, significant increases in glutamate $(P<0.0001$, $t=5.67, \mathrm{DF}=70)$ and total glutamate + glutamine (often designated as Glx $)(P<0.0001, t=5.54, \mathrm{DF}=70)$ levels were found in the mDS. We found no effect of sex in any group, nor for viral transductions in baseline conditions. Contrary to our previous findings [21], CNO treatment in mDS-mCherry animals did provoke significant reductions in glutamate $(P=0.0002, t=4.69$, $\mathrm{DF}=70)$ and total glutamate + glutamine $(P<0.0001, t=6.01$, $\mathrm{DF}=70$ ) levels (Fig. $5 \mathrm{~F}, \mathrm{G}$ ) in the $\mathrm{mDS}$.

\section{DISCUSSION}

We present a novel chemogenetic procedure for selective bilateral activation of nigro-striatal dopamine projections innervating the rat $\mathrm{mDS}$, which enabled us to test behavioral and cerebral metabolic effects of acute dopaminergic modulation of the CSTC circuit. In this animal model, we tested the specific hypothesis that 


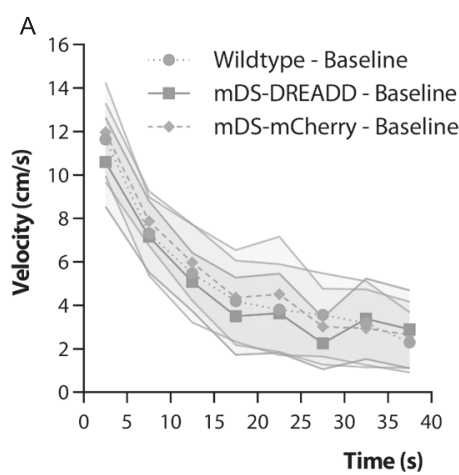

B

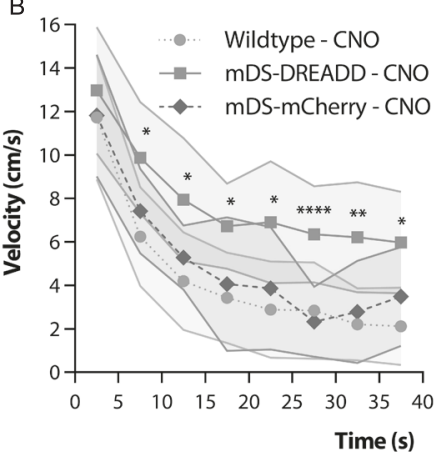

C

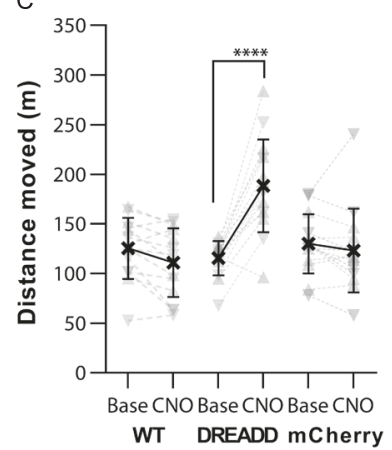

D

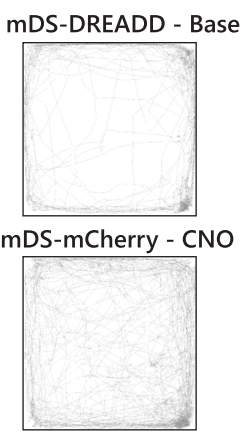

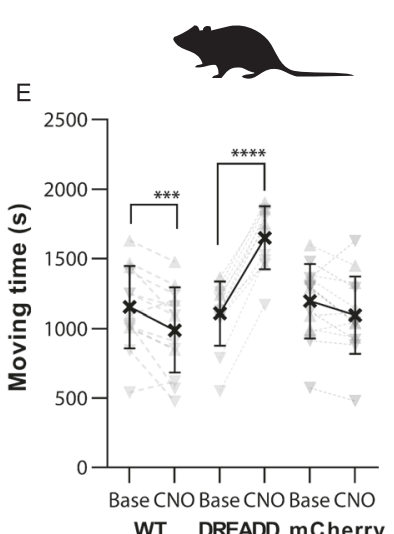
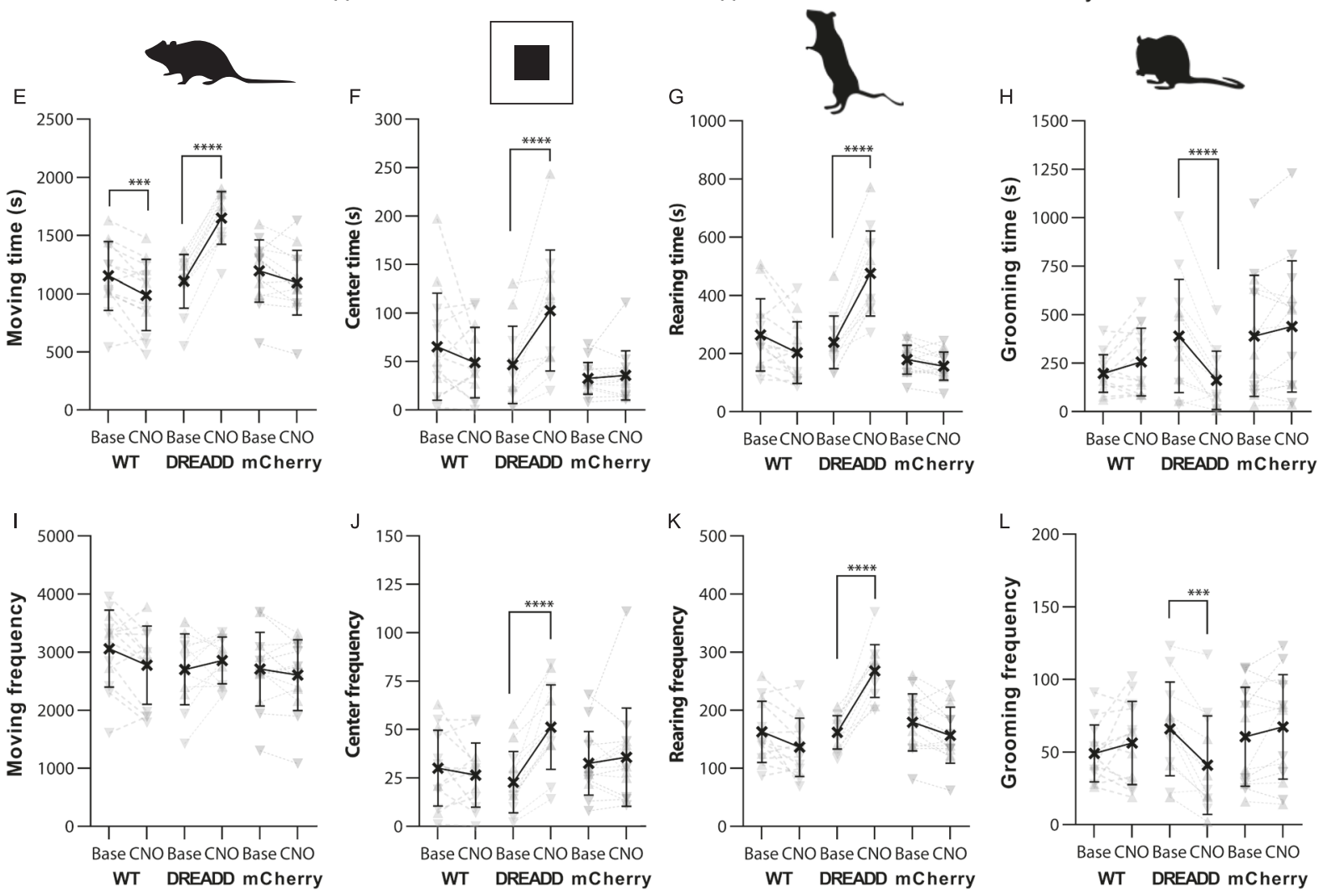

Fig. 2 Open field behavior. A, B Velocity over time in the open field. C Total distance traveled over the whole-time course. D Tracking of the median mDS-DREADD rat before and after CNO. E-H Total time spent moving, in the center of the open field, rearing or grooming. I-L Frequency of movement initiations, entries into the center square, rearings or grooming bouts. $\left(\sigma^{*}=\mathbf{\Lambda}\right)(\boldsymbol{q}=\boldsymbol{\nabla})$.

selective dopamine activation in the rat mDS would lower compulsive-related behaviors and reduce cerebral metabolism in the frontal cortex. Chemogenetics may offer the least invasive, yet regional selective, procedure for rodent studies, in which transduction of Designer Receptors Exclusively Activated by Designer Drugs (DREADD) renders target neurons sensitive to G-protein coupled activation/inactivation following injection of an exogenous ligand such as CNO [25]. By enabling highly selective and reversible activation of specific neuronal subtypes and pathways, chemogenetics presents a powerful approach for establishing causal relationships within neuronal circuits.

\section{Nigro-striatal dopaminergic stimulation increases exploratory behaviors and lowers self-grooming}

We targeted dorsal striatal dopaminergic innervations by using $\mathrm{TH}: \mathrm{Cre}$ rats [18] treated with retrograde neuronal transduction by the AAV6 serotype, as previously established in rats [26], mice [27], and non-human primates [28]. We found that CNO increased locomotor activity in all mDS-DREADD rats. In vivo stimulation of
hM3Dq DREADDs are well known to induce phosphatidylinositol hydrolysis [25], c-fos activation [29-31], dopamine release [32], increased dopamine neuron excitability with a burst firing pattern $[30,31,33,34]$ and ultimately increased locomotion as a behavioral read-out [30, 35-39], in accord with our findings. We also observed an increase in exploratory behaviors, entries into center field, and rearing in all mDS-DREADD rats during chemogenetic activation. Such exploratory behaviors typically increase following treatment with anxiolytic drugs [40, 41], and decrease following stress [41, 42], often in a manner independent of hyperlocomotion, thus suggesting anxiolytic effects of the present perturbation of the CSTC circuit.

Self-grooming is an innate rodent behavior characterized by a sequential pattern of movements [43], which serves as a useful proxy for compulsive behavior [24, 44, 45]. Grooming time and frequency are under control by the efferent activity of striatal SPNs. Whereas activation of $D_{1}$ receptors on SPNs of the direct ("go") pathway increase grooming, activation of $D_{2}$ receptors on the indirect ("no-go") SPNs decrease grooming [43]. Our mDS- 

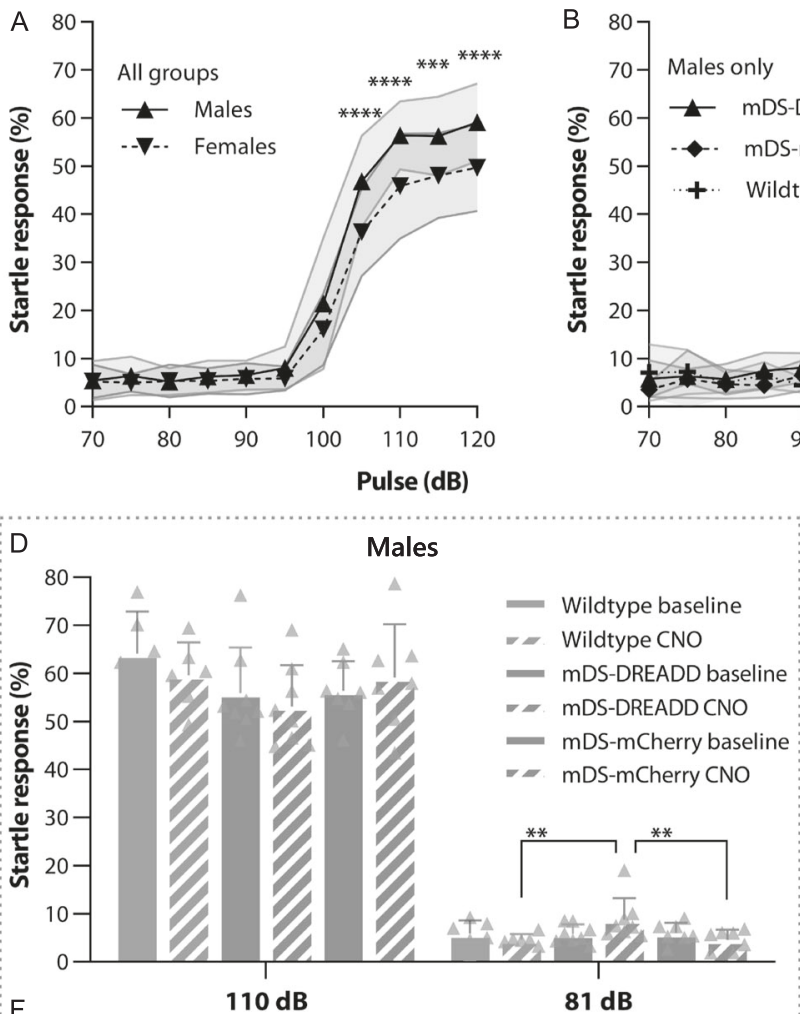

F

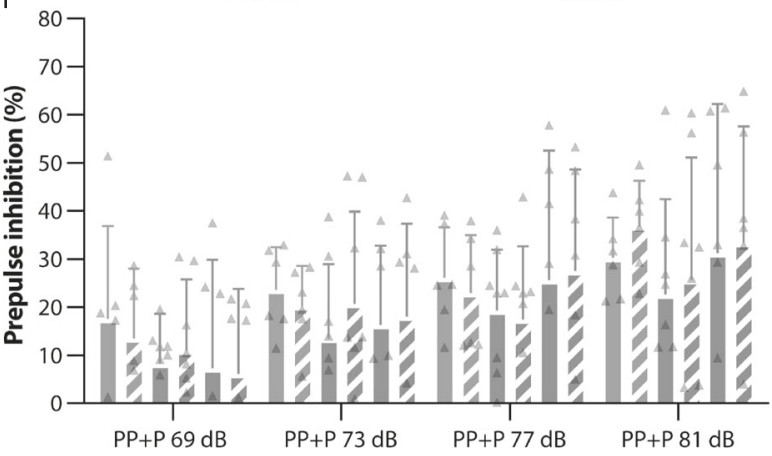

$\mathrm{H}$

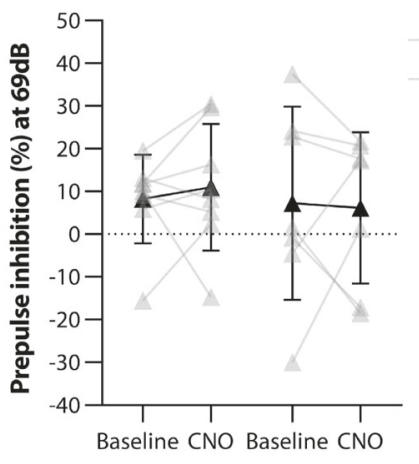

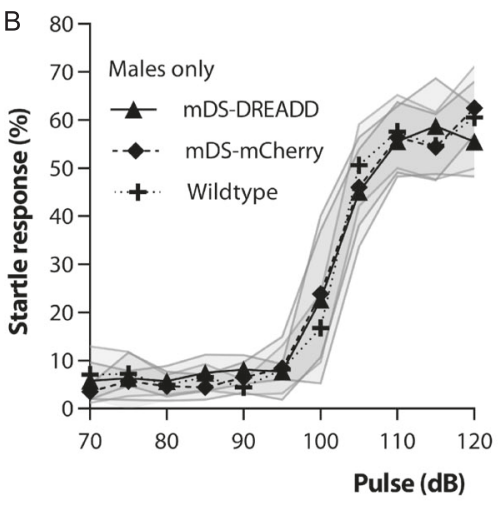

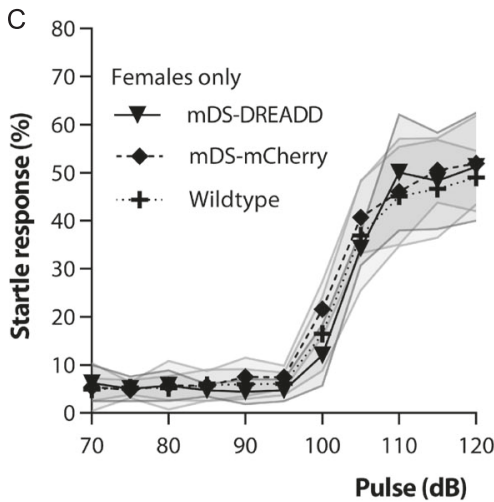

E Females

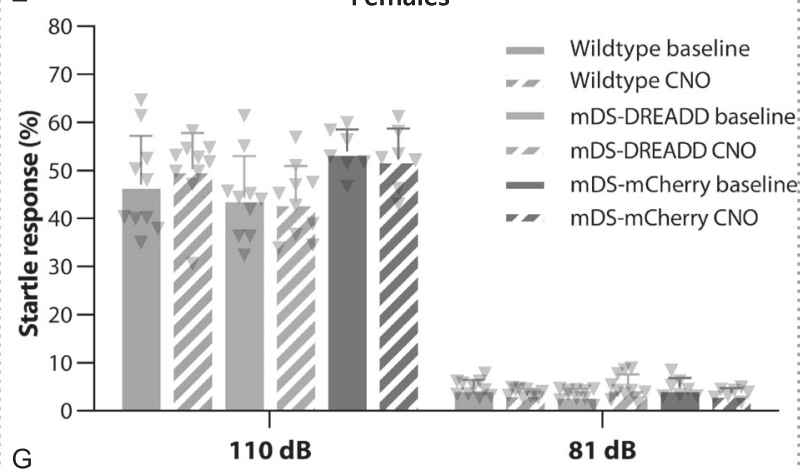

G
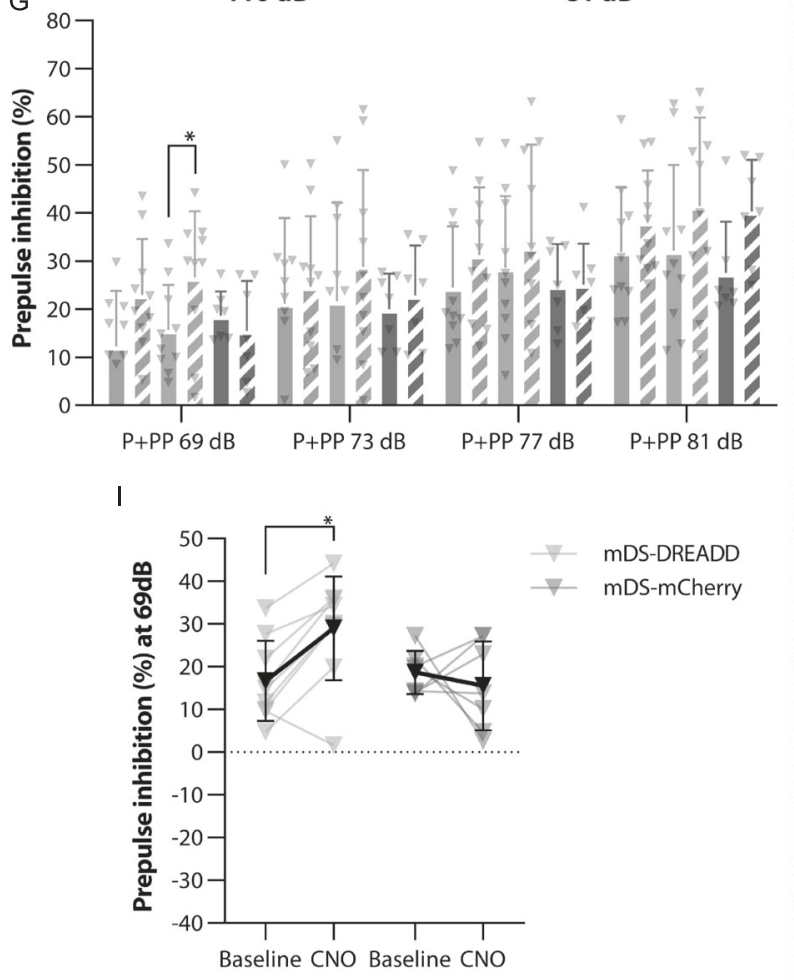

Fig. 3 Acoustic startle response and prepulse inhibition. A-C Startle response to various volumes of pulses. D, E Startle response and effect of mDS-DREADD activation at high volume $(110 \mathrm{~dB})$ pulses and low volume $(81 \mathrm{~dB})$ prepulses. $\mathbf{F}$, $\mathbf{G}$ PPI as a result of prepulse intensities, negative PPI values are not shown in $\mathbf{F}$ and $\mathbf{G}$ to simplify the graph but were included in the statistical analysis. $\mathbf{H}, \mathbf{I}$ All PPI values at the lowest prepulse intensity $(69 \mathrm{~dB})$ pre and post $\mathrm{CNO}$ treatment to activate the nigro-striatal dopaminergic pathway. $\left(\delta^{\hat{\alpha}}=\mathbf{\Delta}\right)(\boldsymbol{q}=\mathbf{\nabla})$.

DREADD rats showed a significant decrease of grooming frequency and duration during chemogenetic activation. This may reflect preferential activation of the $\left(D_{2}\right.$ receptor-expressing) indirect pathway SPNs, although we cannot rule out the possibility of secondary effect due to hyperlocomotion and increased exploration. Direct optogenetic stimulation of the indirect pathway have also shown to reduce excessive grooming in Sapap3knockout mice [46], this supports our conclusion that reductions 

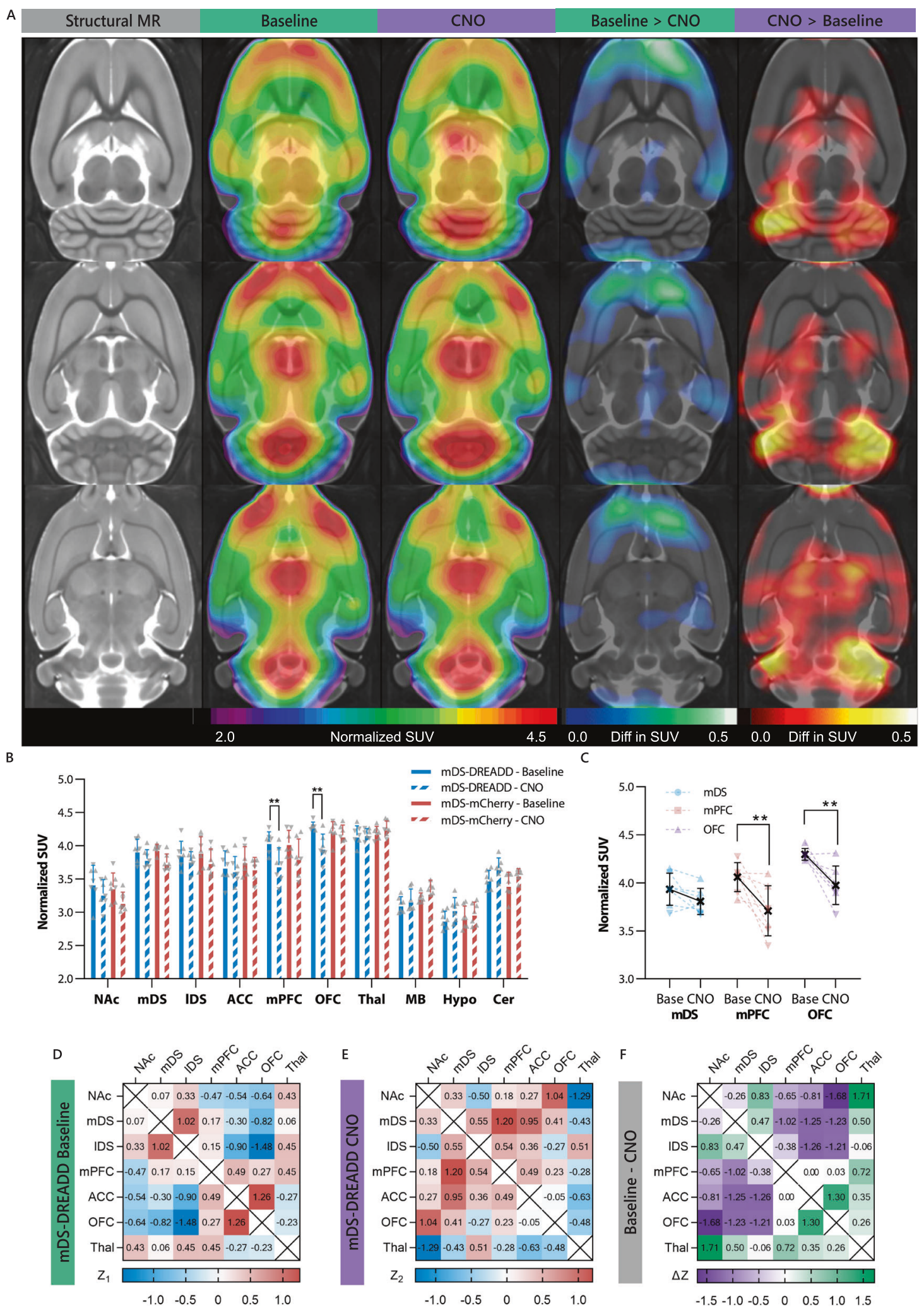

Fig. $4\left[{ }^{18}\right.$ F]FDG images and correlation analysis. A $\left[{ }^{18}\right.$ F]FDG uptake in mDS-DREADD animal at baseline and after chemogenetic (CNO) stimulation (rainbow color), lower metabolic activity (blue color), higher metabolic activity (red color). B Regional standard uptake values at all conditions and $\mathbf{C}$ significant changes and individual animals in $\mathrm{mDS}, \mathrm{mPFC}$, and OFC. $\left({ }^{\star}=\mathbf{\Delta}\right)(\boldsymbol{q}=\boldsymbol{\nabla})$. D Fisher-Z correlations in mDS-DREADD animals at baselines. E Similar correlations in mDS-DREADD animals after chemogenetic stimulations. $\mathbf{F} \Delta Z$ values for each region, showing the total difference between correlations. Nucleus acumbens (NAc), medial dorsal striatum (mDS), lateral dorsal striatum (IDS), anterior cingulate cortex (ACC), medial prefrontal cortex (mPFC), orbitofrontal cortex (OFC), thalamus (Thal), the midbrain including ventral tegmental area and substantia nigra (MB), hypthalamus (Hyp) and cerebellum (Cer). 
A

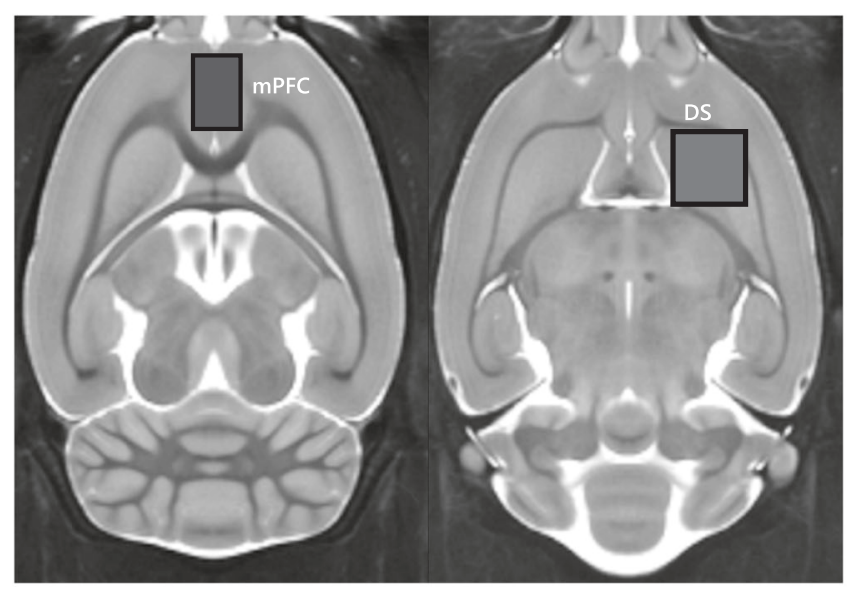

B mPFC

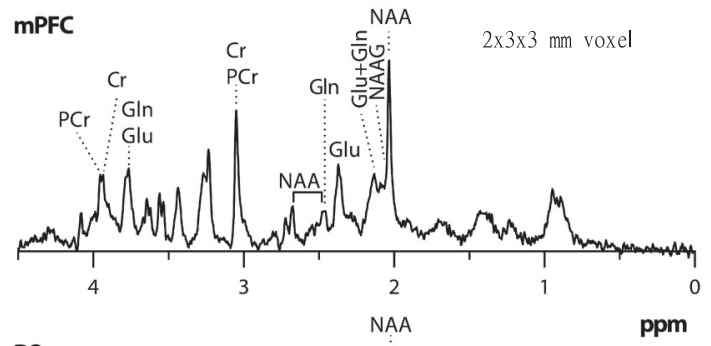

DS
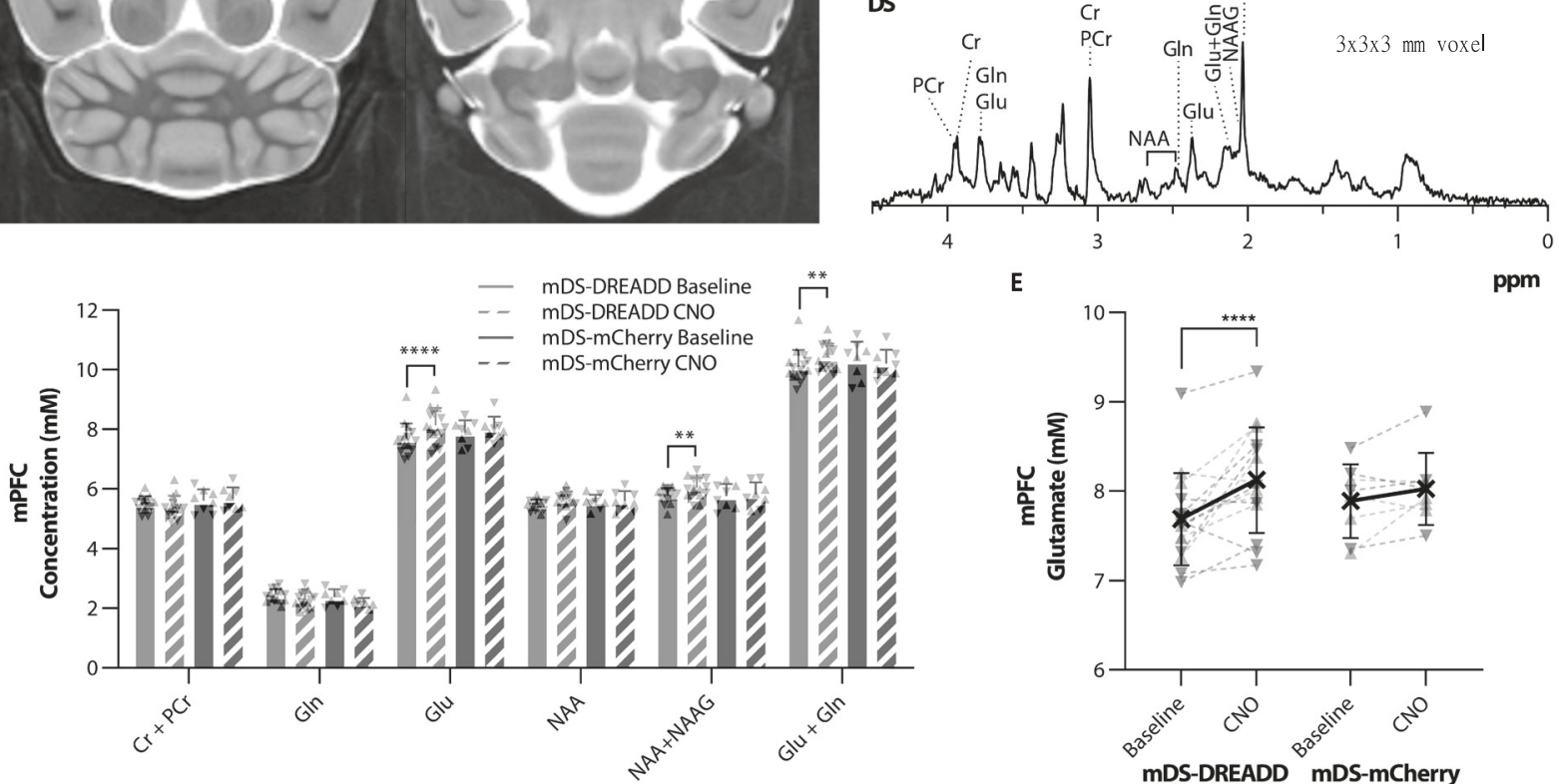

E

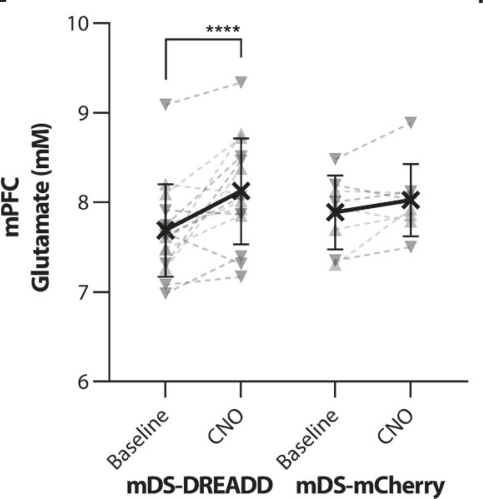

ppm

G

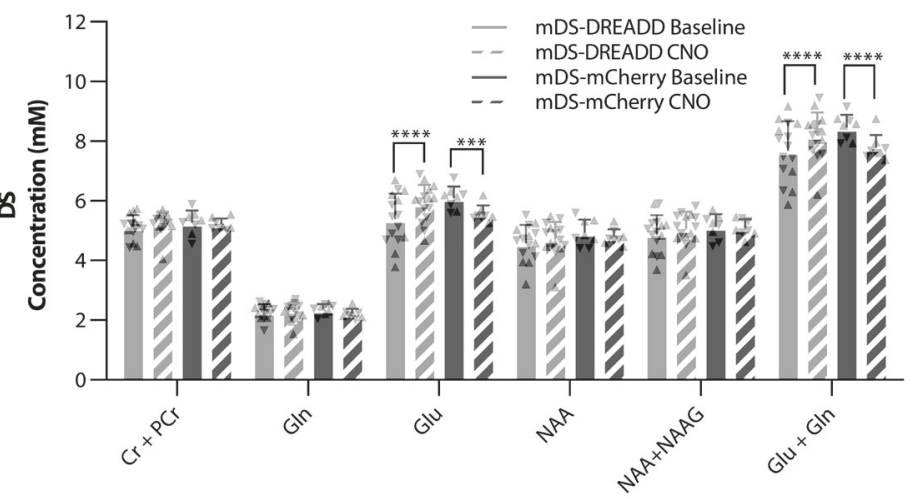

Fig. 5 MR spectroscopy of neurochemicals in mDS-DREADD and mDS-mCherry animals. A Voxel placement in mPFC (blue voxel) and DS (green voxel). B, C Sample spectra from the mPFC and DS. D, F Neurochemical concentrations in the mPFC in all conditions, E, G significant

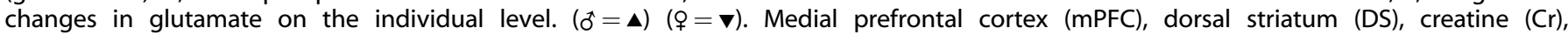
phosphocreatine (PCr), glutamine (Gln), glutamate (Glu), N-acetyl-aspartate (NAA) and N-acetyl-aspartatylglutamate (NAAG).

in grooming are independent of changes in locomotor activity and that it is correlated to D2 receptor activation (which is an inhibitory receptor situated on the indirect pathway). The preferential activation of the indirect pathway in our mDSDREADD rats is supported by a recent report that the dopamine fibers, which was mapped by retrograde tracing, innervating the mDS predominantly target the "indirect" $D_{2}$-positive SPNs [47] (which induces inhibitory action on the indirect pathway). Furthermore, a study by Ahmari et al, showed that hyperactivation of the OFC to DS pathway, increased self-grooming in rats, which support our findings where lower OFC activity leads to lower selfgrooming [45].
Nigro-striatal dopaminergic stimulation affects prepulse inhibition of the acoustic startle response differently in males and females

$\mathrm{PPI}$ is an autonomous behavioral response, which is highly modulated by components of the CSTC circuit, in particular the PFC [48-51], striatum [52], and the SN [53]. Disruption of normal PPI is evident in people with $\mathrm{OCD}[23,54]$. Highly conserved across species, the PPI response serves as a useful translational construct in brain research. While some dopamine agonists disrupt PPI when given systemically, the relative contributions of $D_{1}$-and $D_{2 / 3}$ receptor pathways in this effect are debated [55-58]. Thus, converging lines of clinical and preclinical evidence link the CSTC circuit, dopamine, and PPI. The 
expression of PPI differs between rodent strains $[59,60]$ and sex $[61-$ 63]. Indeed, we found that mDS-DREADD female rats had increased PPI at low prepulse amplitude during chemogenetic activation, but males showed no such effect. Previous work showed that male rats with SN lesions [53] as well as male mice with striatal lesions [64] displayed disruption of PPI, but there was no corresponding investigation of female rats in those studies. In another investigation, deep brain stimulation (DBS) of the NAc disrupted PPI in male WT rats, whereas the same DBS rescued disrupted PPI in a male rat model of schizophrenia [50], which implies context-dependence of the behavior consequences of stimulated dopamine release.

A limitation to this study lies in our use of CNO to activate DREADDs. CNO metabolizes in vivo to clozapine, which is presumably the main agonist on DREADDs [21, 65-67]. While clozapine is an antagonist at endogenous dopamine $D_{2 / 3}$ and serotonin $5-\mathrm{HT}_{2 \mathrm{~A}}$ receptors, it has selectivity for DREADDs when administered at the present low dose. Indeed, we did not observe any behavioral effects of $\mathrm{CNO} / \mathrm{clozapine}$ in control rats in this study, nor had we seen any occupancy at $\mathrm{D}_{2 / 3}$ or $5-\mathrm{HT}_{2 \mathrm{~A}}$ receptors in an earlier in vivo binding experiment [21]. Furthermore, clozapine treatment can restore disrupted PPI [57, 60,68], but neither we nor others [66] have measured any intrinsic effects of CNO on PPI in WT or control animals at the dose used, which also argues for selective activation of DREADDs.

\section{Nigro-striatal dopaminergic stimulation affects metabolic activity in the medial prefrontal cortex and orbitofrontal cortex}

Metabolic mapping of $\left[{ }^{18} \mathrm{~F}\right]$ FDG uptake by PET can identify perturbation of neuronal circuits related to behavior, chemical stimulation, or chemogenetic-induced circuit modulation $[50,51,69-72]$. We found that chemogenetic activation in mDSDREADD rats elicited hypometabolism in fronto-cortical areas (Fig. 4A, B). This confirms the behavioral findings described above suggesting that $\mathrm{mDS}$ dopamine activation controls fronto-cortical neuronal activity though the CSTC circuit. Serveas et al. showed that acute treatment of rats with the dopamine $D_{2 / 3}$ receptor agonist quinpirole provoked a global increase in $\left[{ }^{18} \mathrm{~F}\right] \mathrm{FDG}$ wholebrain uptake, yet a relatively lesser increase in NAc, mDS, and the fronto-cortical regions, i.e. MPFC, ACC and OFC [72], suggesting a common mechanism to the present DREADD study. Globally increased $\left[{ }^{18} \mathrm{~F}\right] \mathrm{FDG}$ uptake might mask regional differences in metabolism, emphasizing the importance of whole-brain normalization between baseline and test conditions [73]. Our use of the human HRRT PET scanner, which has lesser spatial resolution $(2 \mathrm{~mm})$ compared with contemporary dedicated small animal scanners (1 $\mathrm{mm})$, limits our ability to detect small focal changes in metabolism. We accommodate the resolution issue by using relatively large bilateral VOls.

\section{Nigro-striatal dopaminergic stimulation increase glutamate and $\mathrm{N}$-acetylaspartylglutamic acid in medial prefrontal cortex and glutamate levels in dorsal striatum}

Our MR spectroscopy results showed increases in glutamate and NAAG in the mPFC, and increased glutamate in the mDS during chemogenetic activation, which may seem at odds with the PET finding of lower $\left[{ }^{18} \mathrm{~F}\right] \mathrm{FDG}$ uptake in frontal cortex. While the exact relationship between $\left[{ }^{18} \mathrm{~F}\right]$ FDG uptake and total glutamate levels is unknown, we suppose that glutamate is stored in the terminals of glutamatergic afferents in the $\mathrm{MPFC}$, which are presumably thalamic or cortical inputs through the CSTC circuit, while NAAG is mainly located in interneurons [74]. Once released into the synapse, glutamate is taken up by astroglial cells and converted into glutamine, whereas NAAG is metabolized to NAA and glutamate $[75,76]$. In this scenario, the increased glutamate and NAAG levels measured by MR spectroscopy during chemogenetic activation may thus reflect elevated vesicular concentrations in thalamic or cortical afferent terminals, due to indirect inhibition via $\mathrm{mDS}$ dopaminergic activation of the indirect (no-go) pathway. NAAG signaling is not completely understood, but some evidence points towards it having an inhibitory effect on GABA release, such that lower NAAG release might result in net inhibition of corticostriatal projections [77]. Such an inhibition could account for the lower cortical $\left[{ }^{18} \mathrm{~F}\right] \mathrm{FDG}$ uptake and consequently lower glutamatergic activity in the DS, resulting in increased vesicular glutamate content in DS. Furthermore, we suppose that mDS-DREADD stimulation also stimulates dopamine neurons that co-release glutamate $[78,79]$, which in turn might favor the local astroglial conversion of glutamine to glutamate $[75,76]$.

As noted above, there is no general model to connect glutamate levels measured with MRS to $\left[{ }^{18} \mathrm{~F}\right] \mathrm{FDG}$ uptake. One study reported no correlation between these two markers in WT mice, although there was a clear inverse relationship in mGluR5 KO mice [80]. That finding resembles present observations in the mDS-DREADD group, suggesting a similar perturbation of the coupling between glutamate levels and energy metabolism. We did observe a change in DS glutamate levels in the mCherry animals, as in our previous study, albeit at higher doses of CNO [21]. Thus, it remains possible that CNO metabolism to clozapine may indeed contribute to the cerebral metabolic changes reported in this study, albeit in the opposite direction; our results may therefore underestimate the effect of $\mathrm{mDS}$ dopamine activity on local glutamate levels

\section{Translational relevance}

Changes in striatal dopamine and prefrontal cortical glutamate levels are held to be central etiological factors for neuropsychiatric disorders that involve the CSTC circuit, such as OCD [13] and Tourette's Syndrome [81]. In a recent PET study with DBS of the ventral striatum in people with treatment-resistant $O C D$, increased dopamine release correlated with a decline in OCD related symptoms [82]. Furthermore Nordstrom et al. found that systemic administration of the $D_{2 / 3}$ receptor agonist bromocriptine suppressed "Tics" in a transgenic mouse model of Tourette's Syndrome [83], supporting an earlier clinical report that bromocriptine may be helpful in some OCD patients [84]. Our results are a step towards disentangling the functional and metabolic effects of specific elements in the CSTC circuit and support the proposition that $\mathrm{mDS}$ might be a relevant DBS target in neuropsychiatric diseases involving compulsive or impulsive behaviors.

\section{Conclusion}

We found that chemogenetic activation of dopamine neurons projecting to $\mathrm{mDS}$ potentiated rat exploratory behavior, lowered self-grooming, and enhanced PPI of the startle response. These behavioral changes occurred in association with reduced metabolic activity in the frontal cortex as measured by $\left[{ }^{18} \mathrm{~F}\right]$ FDG PET and increased glutamate and NAAG levels in the MPFC as measured by MRS. Our study thus revealed that dopamine signaling in $\mathrm{mDS}$ exerted modulatory control of fronto-cortical metabolic activity and the orchestration of behavior related to CSTC circuit function. These results support our hypothesis that dopamine release in the $\mathrm{mDS}$ can be a driver for reduced cortical metabolism in distal parts of the CSTC circuit and suggest that dopamine activation in the $\mathrm{mDS}$ reduce anxiety and compulsive behaviors.

\section{REFERENCES}

1. Graybiel AM. The basal ganglia. Curr Biol. 2000;10:R509-11. https://doi.org/ 10.1016/s0960-9822(00)00593-5.

2. Ahmari SE, Dougherty DD. Dissecting OCD circuits: from animal models to targeted treatments. Depress Anxiety. 2015;32:550-62.

3. Peters SK, Dunlop K, Downar J. Cortico-striatal-thalamic loop circuits of the salience network: a central pathway in psychiatric disease and treatment. Front Syst Neurosci. 2016;10:1-23.

4. Simpson EH, Kellendonk C. Insights About Striatal Circuit Function and Schizophrenia From a Mouse Model of Dopamine D2 Receptor Upregulation. Biol Psychiatry. 2017;81:21-30. 
5. Howes OD, Kapur S. The Dopamine Hypothesis of Schizophrenia: Version III-The Final Common Pathway. Schizophr Bull. 2009;35:549-62.

6. Denys D, de Vries F, Cath D, Figee M, Vulink N, Veltman DJ, et al. Dopaminergic activity in Tourette syndrome and obsessive-compulsive disorder. Eur Neuropsychopharmacol. 2013;23:1423-31.

7. Zuo $C$, Ma $Y$, Sun B, Peng S, Zhang $H$, Eidelberg D, et al. Metabolic Imaging of Bilateral Anterior Capsulotomy in Refractory Obsessive Compulsive Disorder: an FDG PET Study. J Cereb Blood Flow Metab. 2013;33:880-7.

8. Horwitz B, Swedo SE, Grady CL, Pietrini P, Schapiro MB, Rapoport JL, et al. Cerebral metabolic pattern in obsessive-compulsive disorder: Altered intercorrelations between regional rates of glucose utilization. Psychiatry Res Neuroimaging. 1991;40:221-37.

9. Menzies L, Chamberlain SR, Laird AR, Thelen SM, Sahakian BJ, Bullmore ET. Integrating evidence from neuroimaging and neuropsychological studies of obsessivecompulsive disorder: The orbitofronto-striatal model revisited. Neurosci Biobehav Rev. 2008;32:525-49.

10. Whiteside SP, Port JD, Abramowitz JS. A meta-analysis of functional neuroimaging in obsessive-compulsive disorder. Psychiatry Res Neuroimaging. 2004;132:69-79.

11. Haber SN. Corticostriatal circuitry. Dialogues Clin Neurosci. 2016;18:7-21.

12. Aoki $\mathrm{Y}$, Aoki A, Suwa H. Reduction of $\mathrm{N}$-acetylaspartate in the medial prefrontal cortex correlated with symptom severity in obsessive-compulsive disorder: Metaanalyses of 1 H-MRS studies. Transl Psychiatry. 2012;2:e153-10.

13. Rosenberg DR, Macmaster FP, Keshavan MS, Fitzgerald KD, Stewart CM, Moore GJ. Decrease in caudate glutamatergic concentrations in pediatric obsessivecompulsive disorder patients taking paroxetine. J Am Acad Child Adolesc Psychiatry. 2000;39:1096-103.

14. Rosenberg DR, Mirza Y, Russell A, Tang J, Smith JM, Banerjee SP, et al. Reduced anterior cingulate glutamatergic concentrations in childhood OCD and major depression versus healthy controls. J Am Acad Child Adolesc Psychiatry. 2004;43:1146-53.

15. Palner M, Kjaerby C, Knudsen GM, Cumming P. Effects of unilateral 6-OHDA lesions on $[3 \mathrm{H}]-\mathrm{N}$ - propylnorapomorphine binding in striatum ex vivo and vulnerability to amphetamine-evoked dopamine release in rat. Neurochem Int. 2011;58:243-7.

16. Casteels C, Lauwers E, Bormans G, Baekelandt V, Van Laere K. Metabolicdopaminergic mapping of the 6-hydroxydopamine rat model for Parkinson's disease. Eur J Nucl Med Mol Imaging. 2008;35:124-34.

17. Sala-Bayo J, Fiddian L, Nilsson SRO, Hervig ME, McKenzie C, Mareschi A, et al. Dorsal and ventral striatal dopamine D1 and D2 receptors differentially modulate distinct phases of serial visual reversal learning. Neuropsychopharmacology. 2020;45:736-44

18. Witten IB, Steinberg EE, Lee SY, Davidson TJ, Zalocusky KA, Brodsky M, et al. Recombinase-Driver Rat Lines: Tools, Techniques, and Optogenetic Application to Dopamine-Mediated Reinforcement. Neuron. 2011;72:721-33.

19. Roughan JV, Flecknell PA. Behavioural effects of laparotomy and analgesic effects of ketoprofen and carprofen in rats. Pain. 2001;90:65-74.

20. Keller SH, L'Estrade EN, Dall B, Palner M, Herth M. Quantification accuracy of a new HRRT high throughput rat hotel using transmission-based attenuation correction: A phantom study. 2016 IEEE Nuclear Science Symposium, Medical Imaging Conference and Room-Temperature Semiconductor Detector Workshop (NSS/MIC/RTSD). 2016, pp. 1-3. https://doi.org/10.1109/NSSMIC.2016.8069467.

21. Baerentzen S, Casado-Sainz A, Lange D, Shalgunov V, Tejada IM, Xiong M, et al. The chemogenetic receptor ligand Clozapine $\mathrm{N}$-oxide induces in vivo neuroreceptor occupancy and reduces striatal glutamate levels. Front Neurosci. 2019;13:187.

22. Hoenig K, Hochrein A, Quednow BB, Maier W, Wagner M. Impaired prepulse inhibition of acoustic startle in obsessive-compulsive disorder. Biol Psychiatry. 2005:57:1153-8.

23. Ahmari SE, Risbrough VB, Geyer MA, Simpson HB. Impaired sensorimotor gating in unmedicated adults with obsessive-compulsive disorder. Neuropsychopharmacology. 2012;37:1216-23.

24. Manning EE, Wang AY, Saikali LM, Winner AS, Ahmari SE. Disruption of prepulse inhibition is associated with compulsive behavior severity and nucleus accumbens dopamine receptor changes in Sapap3 knockout mice. Sci Rep. 2021;11:9442.

25. Armbruster BN, Li X, Pausch MH, Herlitze S, Roth BL. Evolving the lock to fit the key to create a family of $G$ protein-coupled receptors potently activated by an inert ligand. Proc Natl Acad Sci USA. 2007;104:5163-8.

26. Salegio EA, Samaranch L, Kells AP, Mittermeyer G, San Sebastian W, Zhou S, et al. Axonal transport of adeno-associated viral vectors is serotype-dependent. Gene Ther. 2013;20:348-52.

27. Aschauer DF, Kreuz S, Rumpel S. Analysis of Transduction Efficiency, Tropism and Axonal Transport of AAV Serotypes 1, 2, 5, 6, 8 and 9 in the Mouse Brain. PLoS One. 2013;8:e76310.

28. San Sebastian W, Samaranch L, Heller G, Kells AP, Bringas J, Pivirotto P, et al. Adeno-associated virus type 6 is retrogradely transported in the non-human primate brain. Gene Ther. 2013;20:1178-83.
29. Szablowski JO, Lee-gosselin A, Lue B, Malounda D, Shapiro MG. Non-invasive control of neural circuits. Nat Biomed Eng. 2018;2:1-11.

30. Mahler SV, Brodnik ZD, Cox BM, Buchta WC, Bentzley BS, Cope ZA, et al. Chemogenetic manipulations of ventral tegmental area dopamine neurons reveal multifaceted roles in cocaine abuse. BioRxiv. 2018;39:503-18.

31. Cho J, Ryu S, Lee S, Kim J, Kim HI. Optimizing clozapine for chemogenetic neuromodulation of somatosensory cortex. Sci Rep. 2020;10:1-11.

32. Mimura K, Nagai $Y$, Inoue KI, Matsumoto J, Hori $Y$, Sato $C$, et al. Chemogenetic activation of nigrostriatal dopamine neurons in freely moving common marmosets. iScience. 2021;24:103066. https://doi.org/10.1016/j.isci.2021. 103066.

33. Sciolino NR, Plummer NW, Chen Y-W, Alexander GM, Robertson SD, Dudek SM, et al. Recombinase-Dependent Mouse Lines for Chemogenetic Activation of Genetically Defined Cell Types. Cell Rep. 2016;15:2563-73.

34. Dell'Anno MT, Caiazzo M, Leo D, Dvoretskova E, Medrihan L, Colasante G, et al. Remote control of induced dopaminergic neurons in parkinsonian rats. J Clin Investig. 2014;124:3215-29.

35. Bonaventura J, Eldridge MAG, Hu F, Gomez JL, Sanchez-Soto M, Abramyan AM, et al. High-potency ligands for DREADD imaging and activation in rodents and monkeys. Nat Commun. 2019;10:4627. https://doi.org/10.1038/s41467-019-12236-z.

36. Runegaard AH, Fitzpatrick CM, Woldbye DPD, Andreasen JT, Sørensen AT, Gether $\mathrm{U}$. Modulating dopamine signaling and behavior with chemogenetics: concepts, progress, and challenges. Pharm Rev. 2019;71:123-56.

37. Jackson BP, Dietz SM, Wightman RM. Fast-scan cyclic voltammetry of 5-hydroxytryptamine. Anal Chem 1995;67:1115-20.

38. Wang S, Tan Y, Zhang JE, Luo M. Pharmacogenetic activation of midbrain dopaminergic neurons induces hyperactivity. Neurosci Bull. 2013;29:517-24.

39. Boender AJ, de Jong JW, Boekhoudt L, Luijendijk MCM, van der Plasse G, Adan RAH. Combined use of the canine adenovirus-2 and DREADD-technology to activate specific neural pathways in vivo. PLoS One. 2014;9:e95392.

40. Prut $L$, Belzung $C$. The open field as a paradigm to measure the effects of drugs on anxiety-like behaviors: a review. Eur J Pharmacol. 2003;463:3-33.

41. Carli M, Prontera C, Samanin R. Effect of 5-HT1A agonists on stress-induced deficit in open field locomotor activity of rats: Evidence that this model identifies anxiolytic-like activity. Neuropharmacology. 1989;28:471-6.

42. Sturman O, Germain PL, Bohacek J. Exploratory rearing: a context- and stresssensitive behavior recorded in the open-field test. Stress. 2018;21:443-52.

43. Berridge KC, Aldridge JW. Super-stereotypy I: Enhancement of a complex movement sequence by systemic dopamine D1 agonists. Synapse. 2000;37:194-204.

44. Kalueff AV, Stewart AM, Song C, Berridge KC, Graybiel AM, Fentress JC. Neurobiology of rodent self-grooming and its value for translational neuroscience. Nat Rev Neurosci. 2016;17:45-59.

45. Ahmari SE, Spellman T, Douglass NL, Kheirbek MA, Simpson HB, Deisseroth K, et al. Repeated cortico-striatal stimulation generates persistent OCD-like behavior. Science. 2013;340:1234-9.

46. Ramírez-Armenta $\mathrm{KI}$, Alatriste-León $\mathrm{H}$, Verma-Rodríguez AK, Llanos-Moreno $\mathrm{A}$, Ramírez-Jarquín JO, Tecuapetla F. Optogenetic inhibition of indirect pathway neurons in the dorsomedial striatum reduces excessive grooming in Sapap3-knockout mice. Neuropsychopharmacology. 2021. https://doi.org/10.1038/s41386-021-01161-9.

47. Lu J, Cheng Y, Xie X, Woodson K, Bonifacio J, Disney E, et al. Whole-Brain Mapping of Direct Inputs to Dopamine D1 and D2 Receptor-Expressing Medium Spiny Neurons in the Posterior Dorsomedial Striatum. Eneuro. 2020. https://doi.org/ 10.1523/ENEURO.0348-20.2020.

48. Bubser $M$, Koch M. Prepulse inhibition of the acoustic startle response of rats is reduced by 6-hydroxydopamine lesions of the medial prefrontal cortex. Psychopharmacology. 1994;113:487-92.

49. Zavitsanou K. Dopamine antagonists in the orbital prefrontal cortex reduce prepulse inhibition of the acoustic startle reflex in the rat. Pharm Biochem Behav. 1999;63:55-61.

50. Bikovsky L, Hadar R, Soto-Montenegro ML, Klein J, Weiner I, Desco M, et al. Deep brain stimulation improves behavior and modulates neural circuits in a rodent model of schizophrenia. Exp Neurol. 2016;283:142-50.

51. Rohleder C, Wiedermann D, Neumaier B, Drzezga A, Timmermann L, Graf R, et al. The Functional Networks of Prepulse Inhibition: Neuronal Connectivity Analysis Based on FDG-PET in Awake and Unrestrained Rats. Front Behav Neurosci. 2016;10:148.

52. Swerdlow NR, Geyer MA, Braff DL. Neural circuit regulation of prepulse inhibition of startle in the rat: Current knowledge and future challenges. Psychopharmacology. 2001;156:194-215.

53. Koch $M$, Fendt $M$, Kretschmer BD. Role of the substantia nigra pars reticulata in sensorimotor gating, measured by prepulse inhibition of startle in rats. Behav Brain Res. 2000;117:153-62.

54. Ahmari SE, Risbrough VB, Geyer MA, Simpson HB. Prepulse inhibition deficits in obsessive-compulsive disorder are more pronounced in females. Neuropsychopharmacology. 2016;41:2963-4. 
55. Rodrigues S, Salum C, Ferreira TL. Dorsal striatum D1-expressing neurons are involved with sensorimotor gating on prepulse inhibition test. J Psychopharmacol. 2017. https://doi.org/10.1177/0269881116686879.

56. Bortolato $M$, Aru GN, Fà $M$, Frau $R$, Orrù $M$, Salis $P$, et al. Activation of $D 1$, but not $D 2$ receptors potentiates dizocilpine-mediated disruption of prepulse inhibition of the startle. Neuropsychopharmacology. 2005;30:561-74.

57. Geyer MA, Krebs-Thomson K, Braff DL, Swerdlow NR. Pharmacological studies of prepulse inhibition models of sensorimotor gating deficits in schizophrenia: a decade in review. Psychopharmacology (Berl). 2001;156:117-54. https://doi.org/ 10.1007/s002130100811.

58. Weber M, Chang W-L, Breier MR, Yang A, Millan MJ, Swerdlow NR. The effects of the dopamine D2 agonist sumanirole on prepulse inhibition in rats. Eur Neuropsychopharmacol. 2010;20:421-5.

59. Plappert CF, Pilz PKD, Schnitzler H-U. Factors governing prepulse inhibition and prepulse facilitation of the acoustic startle response in mice. Behav Brain Res. 2004;152:403-12.

60. Swerdlow N. Discrepant findings of clozapine effects on prepulse inhibition of startle: is it the route or the rat? Neuropsychopharmacology. 1998;18:50-56.

61. Faraday MM. Rat sex and strain differences in responses to stress. Physiol Behav. 2002;75:507-22.

62. Lehmann J, Pryce CR, Feldon J. Sex differences in the acoustic startle response and prepulse inhibition in Wistar rats. Behav Brain Res. 1999;104:113-7.

63. Tylš $F$, Páleníček $T$, Kadeřábek L, Lipski $M$, Kubešová $A$, Horáček J. Sex differences and serotonergic mechanisms in the behavioural effects of psilocin. Behav Pharmacol. 2016;27:309-20.

64. Baldan Ramsey LC, Xu M, Wood N, Pittenger C. Lesions of the dorsomedial striatum disrupt prepulse inhibition. Neuroscience. 2011;180:222-8.

65. Ilg AK, Enkel T, Bartsch D, Bähner F. Behavioral Effects of Acute Systemic LowDose Clozapine in Wild-Type Rats: Implications for the Use of DREADDs in Behavioral Neuroscience. Front Behav Neurosci. 2018;12:173. https://doi.org/ 10.3389/fnbeh.2018.00173.

66. MacLaren DAA, Browne RW, Shaw JK, Krishnan Radhakrishnan S, Khare P, Espana RA, et al. Clozapine N-Oxide Administration Produces Behavioral Effects in Long-Evans Rats: Implications for Designing DREADD Experiments. ENeuro. 2016;3:219-16.

67. Gomez JL, Bonaventura J, Lesniak W, Mathews WB, Sysa-shah P, Rodriguez LA, et al. Chemogenetics revealed: dreadd occupancy and activation via converted clozapine. Science. 2017;357:503-7.

68. De Carolis L, Stasi MA, Serlupi-Crescenzi O, Borsini F, Nencini P. The effects of clozapine on quinpirole-induced non-regulatory drinking and prepulse inhibition disruption in rats. Psychopharmacology. 2010;212:105-15.

69. Apetz N, Kordys E, Simon M, Mang B, Aswendt M, Wiedermann D, et al. Effects of subthalamic deep brain stimulation on striatal metabolic connectivity in a rat hemiparkinsonian model. Dis Model Mech. 2019;12:dmm039065. https://doi.org/ 10.1242/dmm.039065.

70. Urban DJ, Zhu H, Marcinkiewcz CA, Michaelides M, Oshibuchi $H$, Rhea D, et al. Elucidation of The Behavioral Program and Neuronal Network Encoded by Dorsal Raphe Serotonergic Neurons. Neuropsychopharmacology. 2016;41:1404-15. https://doi.org/10.1038/npp.2015.293. Epub 2015 Sep 18.

71. Michaelides M, Anderson SAR, Ananth M, Smirnov D, Thanos PK, Neumaier JF, et al. Whole-brain circuit dissection in free-moving animals reveals cell-specific mesocorticolimbic networks. J Clin Investig. 2013;123:5342-50.

72. Servaes S, Glorie D, Verhaeghe J, Wyffels L, Stroobants S, Staelens S. [18F]-FDG PET neuroimaging in rats with quinpirole-induced checking behavior as a model for obsessive compulsive disorder. Psychiatry Res Neuroimaging. 2016;257:31-38.

73. Borghammer $P$, Cumming $P$, Aanerud J, Gjedde A. Artefactual subcortical hyperperfusion in PET studies normalized to global mean: Lessons from Parkinson's disease. Neuroimage. 2009;45:249-57.

74. Moffett JR, Namboodiri MAA, Neale JH. Enhanced carbodiimide fixation for immunohistochemistry: Application to the comparative distributions of $\mathrm{N}$-acetylaspartylglutamate and $\mathrm{N}$ - acetylaspartate immunoreactivities in rat brain. J Histochem Cytochem. 1993;41:559-70.

75. Bak LK, Schousboe A, Waagepetersen HS. The glutamate/GABA-glutamine cycle: aspects of transport, neurotransmitter homeostasis and ammonia transfer. J Neurochem. 2006;98:641-53.

76. Agarwal N, Renshaw PF. Proton MR spectroscopy - Detectable major neurotransmitters of the brain: Biology and possible clinical applications. Am J Neuroradiol. 2012;33:595-602.

77. Zhao J, Ramadan E, Cappiello M, Wroblewska B, Bzdega T, Neale JH. NAAG inhibits $\mathrm{KCl}$-induced [3H]-GABA release via mGluR3, cAMP, PKA and L-type calcium conductance. Eur J Neurosci. 2001;13:340-6.

78. Sulzer D, Joyce MP, Lin L, Geldwert D, Haber SN, Hattori T, et al. Dopamine neurons make glutamatergic synapses in vitro. J Neurosci. 1998;18:4588-602.

79. Trudeau LÉ. Glutamate co-transmission as an emerging concept in monoamine neuron function. J Psychiatry Neurosci. 2004;29:296-310.
80. Joo YH, Kim YK, Choi IG, Kim HJ, Son YD, Kim HK, et al. In vivo glucose metabolism and glutamate levels in mGluR5 knockout mice: a multimodal neuroimaging study using [18F]FDG microPET and MRS. EJNMMI Res. 2020;10:116. https://doi. org/10.1186/s13550-020-00716-z.

81. Wang Z, Maia TV, Marsh R, Colibazzi T, Gerber A, Peterson BS. The neural circuits that generate tics in Tourette's syndrome. Am J Psychiatry. 2011;168:1326-37.

82. Figee M, Luigjes J, Smolders R, Valencia-Alfonso CE, Van Wingen G, De, et al. Deep brain stimulation restores frontostriatal network activity in obsessive-compulsive disorder. Nat Neurosci. 2013;16:386-7.

83. Nordstrom EJ, Bittner KC, McGrath MJ, Parks CR, Burton FH. Hyperglutamatergic cortico-striato-thalamo-cortical circuit breaker drugs alleviate tics in a transgenic circuit model of Tourette's syndrome. Brain Res. 2015;1629:38-53.

84. Ceccherini-Nelli A, Guazzelli M. Treatment of refractory OCD with the dopamine agonist bromocriptine. J Clin Psychiatry. 1994;55:415-6.

\section{ACKNOWLEDGEMENTS}

Structural reference MR image is generously provided by Kristian Nygaard Mortensen, Center for Translational Neuromedicine, University of Copenhagen. Technical expertise regarding acoustic startle response and prepulse inhibition was generously provided by Kim Fejgin at $\mathrm{H}$. Lundbeck. Radiochemical support was generously provided by Matthias M. Herth and Vladimir Shalgunov, Department of Drug Design and Pharmacology, University of Copenhagen. Statistical discussions with Professor Todd Ogden, Department of Biostatistics, Columbia University, NY. Professor, DM Gitte M. Knudsen, head of the Neurobiology Research Unit, Copenhagen University Hospital, offered her support and guidance for students and researchers throughout the project.

\section{AUTHOR CONTRIBUTIONS}

Conceptualization, CK, MP; methodology, ACS, FG, SLB, DL, SHK, AR, SM, IM, HL, CS, CK, MP; validation, ACS, SLB, MS, SHK, SM, PMF, CK, CS, PC, MP; formal analysis, ACS, SLB, FG, SM, DL, SHK, AR, CS, MP; investigation, PC, MP; resources, AC, MP; data curation, ACS, FG, SLB, DL, AR, IM, MS, CS, PMF, MP; writing-original draft preparation, MP; writing-review and editing, MS, PMF, PC, MP; visualization, MP; supervision, CS, CK, MP; funding acquisition, ACS, MP. All authors have read and agreed to the published version of the manuscript.

\section{FUNDING}

Funding for this project was provided to MP by the Lundbeck Foundation (R192-20151591 and R194-2015-1589), Augustinus Foundation (18-3746 and 17-1982, Independent Research Fund Denmark (5053-00036B), Savværksejer Jeppe Juhls og Hustrus Ovita Juhls Mindelegat and Købmand i Odense Johann og Hanne Weimann født Seedorffs Legat. MS was supported by a Marie Curie Sklodowska Fellowship. CK was supported by grants from the Augustinus Fonden (16-3735) and the Independent Research Fond Denmark (100948). MP is collaborating with the company Compass Pathways Plc (London, UK). MS is a member of the scientific advisory board of Roche Pharmaceuticals. The remaining authors have nothing to disclose. Parts of this manuscript have been presented as posters and preprints Casado et al. Eur. Neuropsych. 27, S689, Baerentzen et al JCBFM 37, 221 and bioRxiv 2021.02.11.430770.

\section{COMPETING INTERESTS}

MP is collaborating with the company Compass Pathways Plc (London, UK). MS is a member of the scientific advisory board of Roche Pharmaceuticals. The remaining authors have nothing to disclose.

\section{ADDITIONAL INFORMATION}

Supplementary information The online version contains supplementary material available at https://doi.org/10.1038/s41386-021-01207-y.

Correspondence and requests for materials should be addressed to Mikael Palner.

Reprints and permission information is available at http://www.nature.com/ reprints

Publisher's note Springer Nature remains neutral with regard to jurisdictional claims in published maps and institutional affiliations. 